\title{
Detection of DNA and Ploidy Variation within Vegetatively Propagated Zoysiagrass Cultivars
}

\author{
Karen R. Harris-Shultz ${ }^{1}$ \\ USDA-ARS, Crop Genetics and Breeding Research Unit, 115 Coastal Way, Tifton, GA 31793 \\ Susana Milla-Lewis \\ Department of Crop Science, Box 7620, North Carolina State University, Raleigh, NC 27695
}

Aaron J. Patton

Department of Agronomy, 915 West State Street, Purdue University, West Lafayette, IN 47907

Kevin Kenworthy

Agronomy Department, Box 110500, University of Florida, Gainesville, FL 32611

Ambika Chandra

Texas AgriLife Research and Extension Center, Texas A\&M University System, Dallas, TX 75252

F. Clint Waltz

Crop and Soil Sciences, Georgia Experiment Station, The University of Georgia, 1109 Experiment

Street, Griffin, GA 30223

George L. Hodnett and David M. Stelly

Department of Soil and Crop Sciences, Texas A\&M University, 370 Olsen Boulevard, College Station, $T X 77843$

\begin{abstract}
AdDITIONAL INDEX WORDS. flow cytometry, octoploid, simple sequence repeat markers, Zoysia
Abstract. Zoysiagrass (Zoysia sp.) is used as a warm-season turfgrass for lawns, parks, and golf courses in the warm, humid and transitional climatic regions of the United States. Zoysiagrass is an allotetraploid species $(2 n=4 x=40)$ and some cultivars are known to easily self- and cross-pollinate. Previous studies showed that genetic variability in the clonal cultivars Emerald and Diamond was likely the result of contamination (seed production or mechanical transfer) or mislabeling. To determine the extent of genetic variability of vegetatively propagated zoysiagrass cultivars, samples were collected from six commercially available zoysiagrass cultivars (Diamond, Emerald, Empire, JaMur, Meyer, Zeon) from five states (Arkansas, Florida, Georgia, North Carolina, Texas). Two of the newest cultivar releases (Geo and Atlantic) were to serve as outgroups. Where available, one sample from university research plots and two samples from sod farms were collected for each cultivar per state. Forty zoysiagrass simple sequence repeat (SSR) markers and flow cytometry were used to compare genetic and ploidy variation of each collected sample to a reference sample. Seventy-five samples were genotyped and an unweighted pair group method with arithmetic mean clustering revealed four groups. Group I (Z. japonica) included samples of 'Meyer' and Empire11 ('Empire' sample at location \#11), Group II (Z. japonica $\times Z$. pacifica) included samples of 'Emerald' and 'Geo', Group III (Z. matrella) included samples of 'Diamond' and 'Zeon', and Group IV ( $Z$. japonica) consisted of samples from 'Empire', 'JaMur', 'Atlantic', and Meyer3 ('Meyer' at sample location \#3). Samples of 'Empire', 'Atlantic', and 'JaMur' were indistinguishable with the markers used. Four samples were found to have alleles different from the respective reference cultivar, including two samples of 'Meyer', one sample of 'Empire', and one sample of 'Emerald'. Three of these samples were from Texas and one of these samples was from Florida. Three of the four samples that were different from the reference cultivar were university samples. In addition, one sample, Empire11, was found to be an octoploid $(2 n=8 x=80)$. For those samples that had a fingerprint different from the reference cultivar, contamination, selfing, and/or hybridization with other zoysiagrasses may have occurred.
\end{abstract}

In the United States, zoysiagrass refers to two perennial species from the genus Zoysia (Z. japonica and Z. matrella) that are used as a warm-season turfgrass for lawns, parks, and

Received for publication 2 Apr. 2014. Accepted for publication 22 May 2014. We thank William Anderson and Joseph Knoll for their comments regarding the manuscript and David Sack and Hongliang Wang for their technical expertise. We also thank Doug Karcher (University of Arkansas), Brian Schwartz (University of Georgia), Kevin Morris (USDA-ARS), and the representatives from the many sod farms that kindly provided samples for our study.

Mention of trade names or commercial products in this publication is solely for the purpose of providing specific information and does not imply recommendation or endorsement by the U.S. Department of Agriculture.

${ }^{1}$ Corresponding author. E-mail: Karen.Harris@ars.usda.gov. golfing surfaces (tees, fairways, roughs, bunker faces) in the warm, humid and transitional climatic regions. In Japan and other countries of East Asia, Z. japonica is also used as a forage grass (Cai et al., 2005; Tsuruta et al., 2005). Zoysiagrasses are slow to establish, require full sun to partial shade, and have high heat and drought tolerance. Differences between the species exist because Z. matrella has narrower leaves, grows more slowly, and is less cold-hardy than $Z$. japonica, yet $Z$. matrella is more tolerant to salinity and insect pests (Patton, 2009). Zoysiagrass has been slowly increasing in use across the United States since it was introduced $\approx 1900$. The cultivars Meyer and Emerald were released in the 1950s and are considered to be the industry standards for zoysiagrass (Patton, 2009). 
Zoysiagrass is an allotetraploid species $(2 n=4 x=40)$ (Arumuganathan et al., 1999; Forbes, 1952) with an estimated genome size of $421 \mathrm{Mb}$ for cultivar Zenith (Arumuganathan et al., 1999). Zoysiagrass has the most genetic tools as compared with the other widely used warm-season turfgrasses such as st. augustine grass (Stenotaphrum secundatum), centipedegrass (Eremochloa ophiuroides), seashore paspalum (Paspalum vaginatum), and common bermudagrass (Cynodon dactylon). The genetic diversity of zoysiagrass species has been characterized with amplified fragment length polymorphisms (Chen et al., 2009), restriction fragment length polymorphisms, random amplified polymorphic DNA markers (Weng et al., 2007; Yaneshita et al., 1999), and even by flavonoids (Anderson et al., 2007). A high-density SSR genomic map has been completed (Li et al., 2009, 2010). Additionally, markers have been identified that are linked to a locus for fall armyworm (Spodoptera frugiperda) resistance (Jessup et al., 2011). Although 1044 SSRs have been developed for zoysiagrass (Cai et al., 2005), most are not publicly available (Jessup et al., 2011); however, a small number of zoysiagrass SSRs have been developed and released (Tsuruta et al., 2005).

From 2001-05, homeowners and landscapers in Georgia and Alabama noticed inconsistent spring green-up patterns in the cultivar Emerald and it was determined that many different genotypes are present, arising from either contamination or mislabeling (Waltz et al., 2005). A previous study examining marker transferability between bermudagrass and zoysiagrass found that sources of the vegetatively propagated zoysiagrass cultivar Diamond from North Carolina and Georgia breeding programs were genetically different (Harris-Shultz et al., 2012). Additionally, some cultivars of zoysiagrass are known to easily self- and cross-pollinate (Harris-Shultz et al., 2012; Kimball et al., 2012a). Because zoysiagrass is not apomictic, it is possible that sod fields could become contaminated by germinating seedlings if zoysiagrass inflorescences were allowed to mature. The objective of this study was to determine the genetic variability and ploidy variation within vegetatively propagated zoysiagrass cultivars.

\section{Materials and Methods}

SAmple Collection and DNA eXtraction. Six popular clonal zoysiagrass cultivars were collected from five states and were examined for within-cultivar variability. 'Diamond',
'Emerald', 'Empire', 'JaMur', 'Meyer', and 'Zeon' (Table 1) were collected from Arkansas, Florida, Georgia, North Carolina, and Texas. These will be referred to in the remainder of the article by the cultivar name and a unique identifier number, which describes the location/source of the specimen collection (Supplemental Table 1). The representative person from each state was responsible for providing a university sample of each cultivar and two samples of each cultivar from sod producers in their state. Because each of the six cultivars selected for this study was not grown for sale in every state, samples were collected based on their availability. Each sample consisted of one or two 10-cm-diameter plugs from a field location of the collector's or sod producer's choosing (Supplemental Table 1). Additionally, a reference sample for each cultivar was collected from the breeder or foundation fields or from K. Morris at the National Turfgrass Evaluation Program. All samples were sent to K. Harris-Shultz and maintained in a temperature-controlled greenhouse. DNA was extracted using a Pure Link Plant DNA Purification kit (Life Technologies Corp., Grand Island, NY), run on a $1 \%$ agarose gel to control for quality, and analyzed using a spectrophotometer (Nanodrop 2000c; Thermo Scientific, Wilmington, DE) to control for DNA quantity.

Forty primer pairs were selected that had been previously identified as being the most polymorphic in a collection of zoysia accessions (Kimball et al., 2012a) (Supplemental Table 2). These primers had been previously developed by Li et al. (2009) and Ma et al. (2007). Each primer pair was added in a $10-\mu \mathrm{L}$ reaction volume that contained $2 \mu \mathrm{L}$ of $5 \times$ reaction buffer (Clear GoTaq $^{\circledR}$; Promega Corp., Madison, WI), $1 \mu \mathrm{L}$ of $25 \mathrm{~mm}$ $\mathrm{MgCl}_{2}, 0.8 \mu \mathrm{L}$ of $2.5 \mathrm{~mm}$ dNTP mix, $0.5 \mu \mathrm{L}$ of M13-tagged forward primer, $2.0 \mu \mathrm{L}$ of reverse primer at $1 \mu \mathrm{M}, 1.8 \mu \mathrm{L}$ of $1 \mu \mathrm{M}$ M13 primer (M13-TGTAAAACGACGGCCAGT) fluorescently labeled with the IRDye ${ }^{\circledR} 700 \mathrm{CW}$ fluorophore (Eurofins MWG Operon, Huntsville, AL), $0.04 \mu \mathrm{L}$ of GoTaq ${ }^{\circledR}$ DNA polymerase (Promega Corp.), $0.86 \mu \mathrm{L}$ of sterile water, and $1 \mu \mathrm{L}$ of $2.5 \mathrm{ng} \cdot \mu \mathrm{L}^{-1}$ DNA. Thermocycler conditions were: an initial denaturation at $94{ }^{\circ} \mathrm{C}$ for $3 \mathrm{~min}, 39$ cycles of $94^{\circ} \mathrm{C}$ for $30 \mathrm{~s}, 45$ to $60{ }^{\circ} \mathrm{C}$ (see Supplemental Table 2) for $1 \mathrm{~min}, 72^{\circ} \mathrm{C}$ for $1 \mathrm{~min}$ $10 \mathrm{~s}$, and a final elongation step at $72{ }^{\circ} \mathrm{C}$ for $10 \mathrm{~min}$. The thermocycler used was a Gene Amp PCR System 9700 dual block (Applied Biosystems, Foster City, CA). Two microliters of polymerase chain reaction (PCR) product were combined with $5 \mu \mathrm{L}$ of Blue Stop (LI-COR ${ }^{\circledR}$ Biosciences, Lincoln, NE) and $0.35 \mu \mathrm{L}$ of this mixture was loaded on a $6.5 \% \mathrm{v} / \mathrm{v}$

Table 1 . Vegetatively propagated zoysiagrass cultivars examined with 40 simple sequence repeat markers. ${ }^{\mathrm{z}}$

\begin{tabular}{|c|c|c|c|}
\hline Cultivar & Zoysia species & Breeder or supplier & $\overline{\mathrm{Yr}}$ \\
\hline Diamond & Z. matrella & Texas AgriLife, Dallas, TX & 1996 \\
\hline JaMur & Z. japonica & Bladerunner Farms, Poteet, TX & 2002 \\
\hline Zeon & Z. matrella & Bladerunner Farms & 1996 \\
\hline Empire & Z. japonica & Sod Solutions, Mount Pleasant, SC & 2000 \\
\hline Geo & Z. japonica $\times Z$. pacifica & Sod Solutions & 2011 \\
\hline
\end{tabular}

zTable information from Patton (2009) with the exception of the cultivars Empire and JaMur, which was obtained from information obtained from plant patents (Doguet, 2002; Gurgel and Ito, 2000).

${ }^{y}$ Previously referred to as a cross between $Z$. japonica and Z. tenuifolia. In the literature, Z. pacifica has been previously incorrectly referred to as Z. tenuifolia (Anderson, 2000).

${ }^{\mathrm{x}}$ Not yet released. 
acrylamide gel and run on a LI-COR ${ }^{\circledR}$ Biosciences 4300 DNA Analyzer. Gel images were scored visually and coded as a " 1 " for presence of a band or " 0 " for absence of a band for each accession for each marker. Sequences for the 10 chloroplastspecific simple sequence repeat length polymorphism (CpSSRLP) markers (Karaca et al., 2002) and 11 zoysiagrass SSR markers (Jessup et al., 2011; La Mantia et al., 2011; Tsuruta et al., 2005) were amplified on samples JaMur1 and Empire1 using the parameters as described previously with the exception of the La Mantia et al. (2011) primers. For the La Mantia et al. (2011) zoysiagrass primers, each reaction contained $1.0 \mu \mathrm{L}$ of $5 \times$ Clear GoTaq $^{\circledR}$ reaction buffer, $1 \mu \mathrm{L}$ of $25 \mathrm{~mm} \mathrm{MgCl}_{2}, 1.0 \mu \mathrm{L}$ of $2.5 \mathrm{~mm}$ dNTP mix, $0.5 \mu \mathrm{L}$ of M13tagged forward primer, $2.0 \mu \mathrm{L}$ of reverse primer at $1 \mu \mathrm{M}, 1.8 \mu \mathrm{L}$ of $1 \mu \mathrm{M} \mathrm{M} 13$ primer (M13-TGTAAAACGACGGCCAGT) fluorescently labeled with the IRDye ${ }^{\circledR} 700 \mathrm{CW}$ fluorophore, $0.05 \mu \mathrm{L}$ of $\mathrm{GoTaq}^{\circledR} \mathrm{DNA}$ polymerase, $0.86 \mu \mathrm{L}$ of sterile water, and $1 \mu \mathrm{L}$ of $2.5 \mathrm{ng} \cdot \mu \mathrm{L}^{-1} \mathrm{DNA}$. Thermocycler conditions were: an initial denaturation at $94^{\circ} \mathrm{C}$ for $3 \mathrm{~min}, 35$ cycles of $94^{\circ} \mathrm{C}$ for $40 \mathrm{~s}, 53^{\circ} \mathrm{C}$ for $40 \mathrm{~s}, 72{ }^{\circ} \mathrm{C}$ for $30 \mathrm{~s}$, and a final elongation step at $72{ }^{\circ} \mathrm{C}$ for $4 \mathrm{~min}$.

Data ANALYSIS. Marker data were imported into NTSYSpc (Rohlf, 2008). Genetic similarity between each pair of accessions was calculated using the SIMQUAL module using the DICE coefficient of similarity (Nei and Li, 1979). A dendrogram was generated from the similarity matrix by using the unweighted pair group method with arithmetic mean clustering procedure in the SAHN module of NTSYSpc. Bootstrap resampling was performed using the software program FreeTree (Hampl et al., 2001) with 500 bootstrap repetitions. Because FreeTree does not allow missing data, those markers that contained missing data were removed. Bootstrap values greater than 50 are noted in Figure 1.

FLOW CYTOMETRY. Zoysiagrass samples were processed and analyzed on a flow cytometer (BD Accuri C6; Becton Dickinson and Co., Franklin Lakes, NJ) by first adding $1000 \mu \mathrm{L}$ of Tris$\mathrm{MgCl}_{2}$ nuclei extraction buffer (Pfosser et al., 1995) to 0.02 to $0.03 \mathrm{~g}$ of fresh leaf tissue using a modified protocol (Galbraith, 2009). For each sample of a cultivar, the reference stock of that cultivar was cochopped with each sample. For comparison of the ploidy between the cultivars, the reference stock of each cultivar was cochopped with the reference stock of another cultivar. This procedure was repeated until the ploidies of all cultivars were examined. Tissue was chopped using a double-edged razor blade (Astra Superior Platinum; ZAO Petersburg Products, St. Petersburg, Russia) until fully macerated. The resulting slurry was then pipetted into a 50- $\mu \mathrm{m}$ disposable filter (CellTrics; Partec, Munster, Germany) sitting on top of a plastic

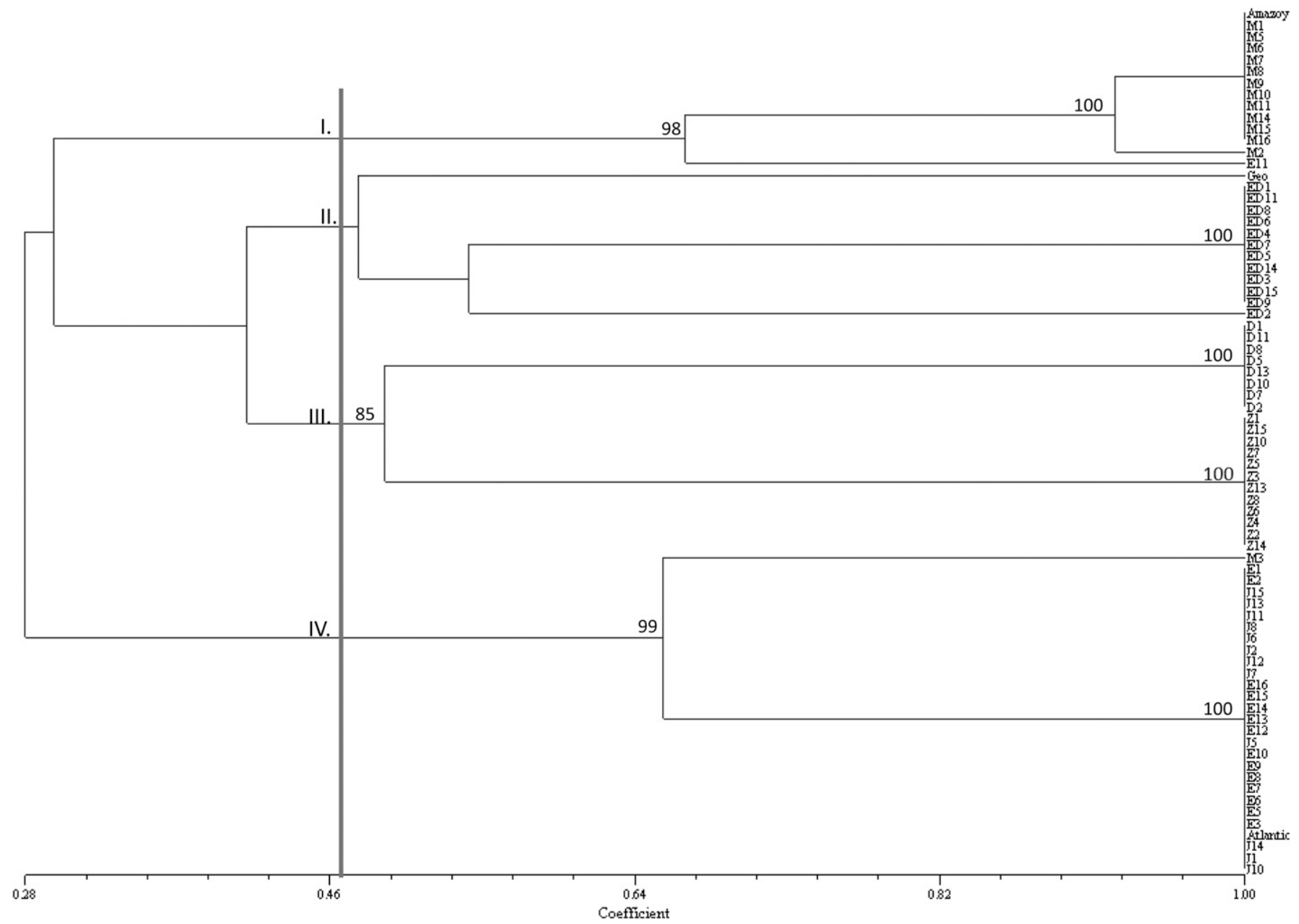

Fig. 1. Unweighted pair group method with arithmetic averages (UPGMA) dendrogram of 75 vegetatively propagated zoysiagrass samples representing six cultivars. Bootstrap values greater than $50 \%$ are shown. All samples were found to be tetraploids except sample E11, which is an octoploid; $M=$ 'Meyer', ED = 'Emerald', D = 'Diamond', $\mathrm{Z}=$ = 'Zeon', E = 'Empire', J = 'JaMur'. 
$12 \times 75-\mathrm{mm}$ culture tube. The filter was removed and $500 \mu \mathrm{L}$ of Rnase/propidium iodide solution (BD Biosciences, San Jose, CA) was added to each filtered sample. Samples were then placed on ice for $15 \mathrm{~min}$ and then run on the device using gating that selected objects that exhibited a strong correlation between the FL-2, fluorescence signals screened with a 585/20-nm bandpass filter, and FL-3 signals, fluorescence signals screened with a 670-nm longpass filter. At least 50,000 events were collected for each sample, the flow rate was set to slow (14 $\left.\mu \mathrm{L} \cdot \mathrm{min}^{-1}\right)$, and the mean FL-2 and $\mathrm{CV}$ were recorded for the Gap 1 (G1) and G2 peaks. Ploidy level was determined based on the $\mathrm{G} 1$ and G2 sample peaks relative to the control G1 and G2 peaks.

Cytology. The zoysiagrass plants Empire11 and Meyer1 were shipped to Texas, subdivided, and initially grown in small pots $(\approx 15 \mathrm{~cm}$ diameter) of commercial potting soil (Fafard 52 ; Sun Gro Horticulture, Agawam, MA) in a heated glasshouse, but growth was anemic and so they were moved into an indoor hallway where they were illuminated by light-emitting diode (LED) grow lights (LumiGrow ES330; LumiGrow, Novato, $\mathrm{CA}$ ) using maximum levels of red and blue LED lighting. Once plants were rejuvenated, $1.5-\mathrm{cm}$ root tips were harvested and pre-treated with alpha-bromonaphthalene (saturated) for $90 \mathrm{~min}$ at room temperature, then fixed in 95\% ethanol-acetic acid (3:1) fixative for at least $24 \mathrm{~h}$, and then rinsed in water for $60 \mathrm{~min}$. Excised meristematic tips were placed in $0.2 \mathrm{~N} \mathrm{HCl}$ for $30 \mathrm{~min}$ at $37^{\circ} \mathrm{C}$, rinsed three times in water $15 \mathrm{~min}$ each, and placed in an enzyme solution of $30 \%$ cellulase (Sigma-Aldrich, St. Louis, MO) and $15 \%$ pectolyase (Sigma-Aldrich) in $0.1 \mathrm{M}$ citrate buffer at $37{ }^{\circ} \mathrm{C}$ for 40 to $50 \mathrm{~min}$, rinsed with distilled water, placed on a clean glass slide with a drop of ethanol-acetic acid (3:1) fixative, macerated using fine-pointed forceps, and allowed to air-dry. Dried slides were then stained with azure B (SigmaAldrich), 25 to $200 \mu \mathrm{g} \cdot \mathrm{mL}^{-1}$ of $0.1 \mathrm{M}$ phosphate buffer at $\mathrm{pH}$ 6.4 to 7.0 Azure B (Halfmann et al., 2007). Stained chromosome spreads were viewed under brightfield illumination using a light microscope (Universal II; Zeiss, Oberkochen, Germany); good spreads were evaluated under oil immersion optics (numerical aperture $=1.40)$ and digital images of the best spreads were captured using a color camera (Microfire; Optronics, Goleta, CA).

\section{Results and Discussion}

Seventy-five samples were examined of the cultivars Diamond, Emerald, Empire, Meyer, JaMur, and Zeon. which also included two newly released zoysiagrass cultivars, Geo and Atlantic (Sod Solutions, Mount Pleasant, SC). which served as outgroups (Supplemental Table 1). A single university sample and two samples from sod farms were obtained, if available, for the six cultivars from each state. For all of the accessions, a maximum of only two alleles was seen for most primer pairs with the exception of Meyer2, which frequently displayed a third faint allele. More than two fragments were seen per accession for five primer pairs (b01012, b06n05, GBZJM029, GBZJM039, GBZJM110) but these are likely non-specific amplification or homologous loci given the wide range of size variation. Although zoysiagrass is a polyploid, many studies that have used SSR markers have identified only one or two alleles per cultivar (Cai et al., 2005; Tsuruta et al., 2005). Linkage analysis supports disomic inheritance (Cai et al., 2005), but observations of more than two alleles per accession have been reported (La Mantia et al., 2011; Li et al., 2009).
Forty SSR markers were amplified on these 75 samples and a dendrogram was produced (Fig. 1). Using a genetic similarity cutoff of 0.48 , the samples were differentiated into four groups. Group I contained the 'Meyer' samples (Z. japonica) and Empire11. Group II consisted of the 'Emerald' (Z. japonica $\times$ Z. pacifica) and 'Geo' (Z. japonica $\times Z$. pacifica) samples. Group III consisted of the 'Diamond' and 'Zeon' samples (Z. matrella), and Group IV consisted of samples of 'Empire', 'JaMur' as well as the 'Atlantic' and Meyer3 sample (Z. japonica). Of interest, cultivars Empire, Atlantic, and JaMur were indistinguishable using these 40 primer pairs. Both 'Empire' and 'JaMur' are cultivars that were both filed for patent in 1998 (Doguet, 2002; Gurgel and Ito, 2000). 'JaMur' was discovered from a collection of plants in Japan made by Jack Murray, whereas 'Empire' was discovered on a Brazilian turf farm (Doguet, 2002; Gurgel and Ito, 2000). The pedigree of cultivar Atlantic is unknown because its patent is pending. Kimball et al. (2012a) reported a single sample of 'Empire' and a single sample of 'JaMur' had a genetic similarity of 0.75 . A list of primers was obtained for SSRs that were polymorphic between the two samples in their study. Most of these primers have been run in this current study and no polymorphism was observed. DNA was re-extracted from JaMur1, JaMur5, Empire1, Empire5, and Emerald9 and DNA was amplified with a subset of these primers (seven primer pairs). No polymorphisms were seen between the 'JaMur' and 'Empire' samples. To identify polymorphic fragments between 'Empire' and 'JaMur', 10 CpSSRLP markers (Karaca et al., 2002) and 11 zoysiagrass SSR markers (Jessup et al., 2011; La Mantia et al., 2011; Tsuruta et al., 2005) were used to amplify DNA from the reference cultivar samples of 'Empire' and 'JaMur'. No differences were seen between the 'Empire' and 'JaMur' reference cultivar samples using these markers. A plausible explanation of why differences were seen between 'Empire' and 'JaMur' in the Kimball et al. (2012a) study, despite using the same primer pairs, is that the authors used vegetative clones of a different genotype than the samples of 'Empire' and 'JaMur' evaluated in this study.

Cultivars that are genetically similar, and often very difficult to distinguish genotypically or phenotypically, are commonly found in turfgrass. Cultivar genetic similarity is the result of the use of natural or induced off-types or well-defined areas with noticeable differences in plant morphology in cultivars that are then released as new cultivars or the accidental release of existing cultivars. For example, the bermudagrass cultivar Tifdwarf is a natural somatic mutant of 'Tifgreen' and was found in golf greens (Burton, 1966). Examination of 'Tifdwarf' with 70 SSR markers identified only two fragments that were unique to 'Tifdwarf' as compared with 'Tifgreen' (Harris-Shultz et al., 2011). Furthermore, many of these nearly genetically identical cultivars have reported pedigrees that are incorrect. For example, the bermudagrass 'TifEagle' was reported to be an off-type derived from 'Tifway 2' (Hanna and Elsner, 1999) but is actually derived from 'Tifgreen' (Kamps et al., 2011; Wang et al., 2010) and the seashore paspalum cultivars Seadwarf, Temple2, SeaIsle 1, and Taliaferra were indistinguishable using 80 SSR markers despite diverse reported collection locations (Harris-Shultz et al., 2013).

From the dendrogram, it was immediately apparent that samples Meyer2, Meyer3, Empire11, and Emerald2 did not match the fingerprint of the reference cultivar. For all the primer pairs examined, sample Meyer2 had all of the reference 
'Meyer' alleles and often (nine of 40 SSR primer pairs) an additional faint allele indicating that this sample is likely 'Meyer' with a contaminating zoysiagrass. This contaminating zoysiagrass did not match any of the genotypes examined. Empire1 1 is genetically similar (0.679) to 'Meyer' and may be derived from a 'Meyer' cross with an unknown grass, but for two primer combinations, a03k14 and b02c05, a 'Meyer' allele was not seen. Emerald2 is likely a cross of 'Emerald' with another zoysiagrass, because Emerald 2 had an 'Emerald' allele for the 40 primer pairs used. Meyer3 may be derived from a cross with 'Empire'/ 'JaMur'/'Atlantic', yet for two primer pairs (b06n05, Ta148), an 'Empire'/'JaMur'/‘Atlantic' allele was not seen.

A previous study had noted that 'Empire' and 'JaMur' had statistically different $2 \mathrm{C}$ DNA contents $(0.88$ and $0.84 \mathrm{pg}$, respectively) (Schwartz et al., 2010). Examination of all 'Empire' and 'JaMur' samples from the greenhouse found no difference between the FL-2 means of 'Empire' (mean = 28,742.00; $\mathrm{SD}=1328.11)$ and 'JaMur' samples (mean $=$ $29,227.20 ; \mathrm{SD}=1951.424)$ on the flow cytometer. Furthermore, when the samples were cochopped, a single G1 peak was seen. All samples were cochopped with their reference cultivar to eliminate artifacts. No difference in ploidy was seen between any of the samples except sample Empire11, which consistently ran as twice the FL-2 mean of 'Empire' when the samples were cochopped ('Empire': FL-2 mean 29,000, 1.94\% cv; Empire 11: FL-2 mean $59,000,1.97 \% \mathrm{CV}$ ) or run alone (Empire1 alone: FL-2 mean 32,000, 3.6\% CV; Empire11 alone: FL-2 mean $63,000,3.11 \% \mathrm{cv})$. Empire11 was obtained from the University of Florida and all reported cytological studies of Zoysia species have determined $2 n=4 x=40$ or $2 n=2 x=20$ (Gould and Soderstrom, 1974; Schwartz et al., 2010). The chromosome number of Empire 11 was determined using root tip spreads and was found to be $2 n=8 x=80$ (Fig. 2).

The mechanism (i.e., somatic chromosome doubling or the fertilization of unreduced gametes) of polyploidization of Empire11 is unknown but dinitroaniline herbicides are commonly used as a pre-emergent herbicide in turfgrass (McCullough et al., 2013). Dinitroaniline herbicides are mitosis-inhibiting herbicides that are used for in vitro chromosome doubling (Dhooghe et al., 2011). Indeed, the field from which Empire11 was harvested had been treated with prodiamine (Barricade; Syngenta Crop Protection, Greensboro, NC) at least once per year since it was installed in 2005 (K. Kenworthy, personal communication). The discovery of a natural octoploid zoysiagrass is particularly exciting because all zoysiagrass cultivars are fertile and $4 x$ and thus capable of exchanging pollen to create seedlings with a different genotype than the parent. Zoysiagrass seedlings with different genotypes than the parental genotype could look different and thus detract from visual uniformity, which is demanded in turfgrass. To eliminate or reduce possible outcrossing events, breeders could develop sterile hybrids by crossing different plants of different ploidy levels, which has been done extensively in bermudagrass (Burton, 1974). Crosses between different ploidy levels in turfgrass have been quite common and the progeny are screened for desirable turfgrass traits (Taliaferro, 1995).

As for the purity of the six cultivars in five states, only four were identified as having genotypes different from the reference cultivar. Excluding the reference sample, two of 12 samples of 'Meyer' were different from the reference sample, one of 14 samples of 'Empire' was different from the reference sample, and one of 11 samples of 'Emerald' was different from the reference sample. Of the four samples, three were from Texas and one was from Florida. Of these four samples that possessed genotypes different from the reference, three of these were university samples and only one sample currently under sod production in Texas varied from the reference sample. No differences were detected between samples of 'Diamond', 'Zeon', or 'JaMur' when compared with the respective reference genotypes. These data indicate, in general, most of the samples received were genotypically similar to the reference cultivar despite these cultivars being fully fertile indicating that management practices are sufficient for genetic purity. Past problems with the production of ' $U-3$ ' common bermudagrass (Anderson et al., 2001), 'Raleigh' st. augustinegrass (Kimball et al., 2012b), and 'Emerald' zoysiagrass (Waltz et al., 2005) indicate that outcrossing, selfing, or contamination in production fields can occur leading to highly variable turf performance. Furthermore, these data indicate that the genetic purity of 'Emerald' has improved since the Waltz et al. (2005) study. This study also illustrates the usefulness of molecular markers
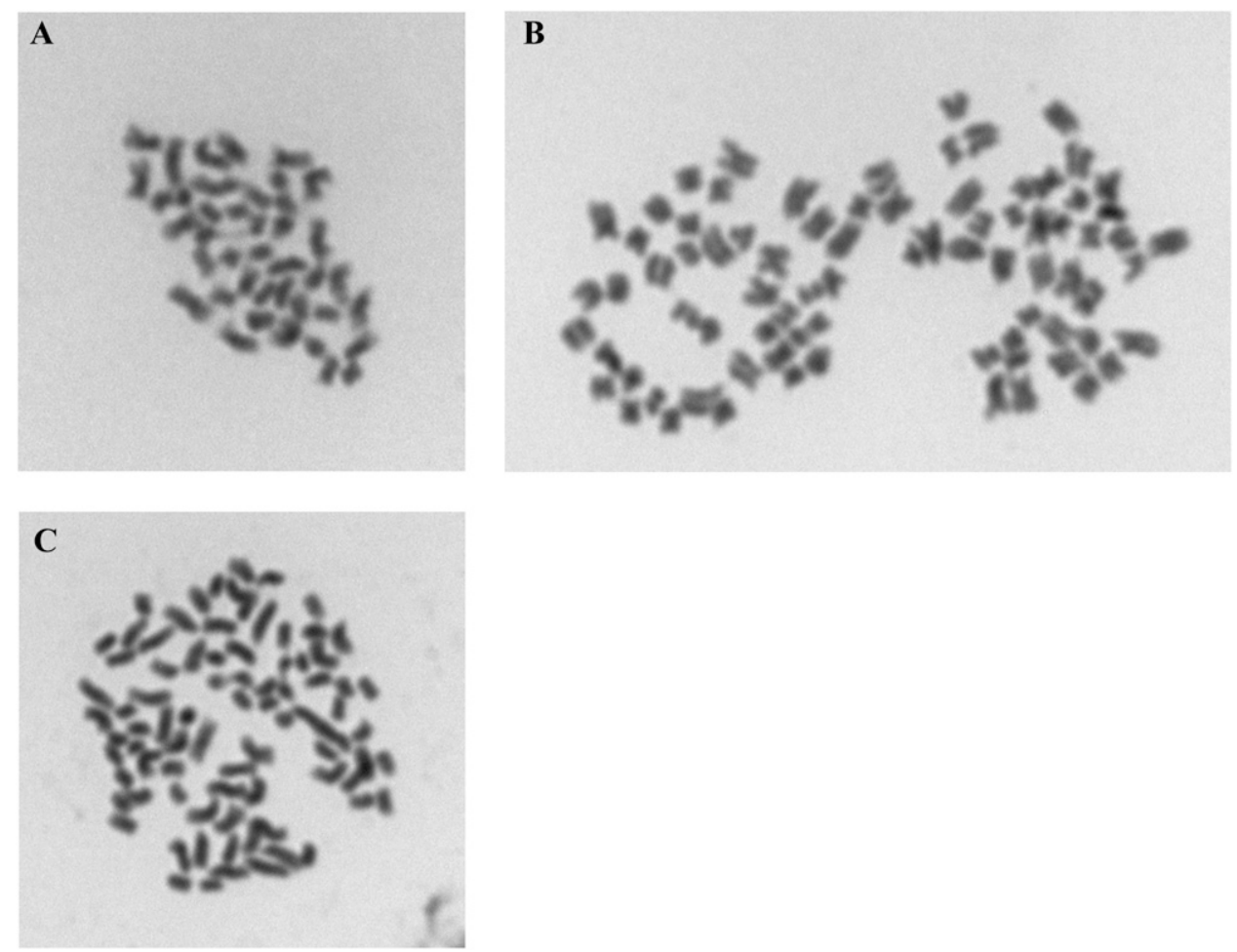

Fig. 2. Images of root-tip chromosome spreads from zoysiagrass Meyer1 (A) and Empire11 (B-C) at metaphase taken at $100 \times$ magnification (numerical aperture $=1.40$ ). 
for identifying and preserving vegetatively propagated cultivars and for the detection of genetic variants in turfgrass breeding programs and sod production fields. Owners of the four samples different from the reference sample were notified so that this material can be relabeled or perhaps used for other purposes.

\section{Literature Cited}

Anderson, M.P., C.M. Taliaferro, D.L. Martin, and C.S. Anderson. 2001. Comparative DNA profiling of U-3 turf bermudagrass strains. Crop Sci. 41:1184-1189.

Anderson, S.J. 2000. Taxonomy of Zoysia (Poaceae): Morphological and molecular variation. PhD diss., Texas A\&M Univ., College Station, TX.

Anderson, W.F., M.E. Snook, and A.W. Johnson. 2007. Flavonoids of zoysiagrass (Zoysia spp) cultivars varying in fall armyworm (Spodoptera frugiperda) resistance. J. Agr. Food Chem. 55:1853-1861.

Arumuganathan, K., S.P. Tallury, M.L. Fraser, A.H. Bruneau, and R. Qu. 1999. Nuclear DNA content of thirteen turfgrass species by flow cytometry. Crop Sci. 39:1518-1521.

Burton, G.W. 1966. Tifdwarf bermudagrass (Reg. No. 8). Crop Sci. 6:94. Burton, G.W. 1974. Breeding bermudagrass for turf, p. 18-22. In: Roberts, E.C. (ed.). Proc. Second Intl. Turfgrass Res. Conf. Amer. Soc. Agron., Madison, WI.

Cai, H.-W., M. Inoue, N. Yuyama, W. Takahashi, M. Hirata, and T. Sasaki. 2005. Isolation, characterization and mapping of simple sequence repeat markers in zoysiagrass (Zoysia spp.). Theor. Appl. Genet. 112:158-166.

Chen, Z., M.L. Wang, C. Waltz, and P. Raymer. 2009. Genetic diversity of warm-season turfgrass: Seashore paspalum, bermudagrass, and zoysiagrass revealed by AFLPs. Floriculture Ornamental Biotechnol. 3:20-24.

Dhooghe, E., K.V. Laere, T. Eeckhaut, L. Leus, and J.V. Huylenbroeck. 2011. Mitotic chromosome doubling of plant tissue in vitro. Plant Cell Tissue Organ Cult. 104:359-373.

Doguet, D. 2002. Zoysiagrass plant named 'JaMur'. U.S. Plant Patent 13178. U.S. Patent Trademark Office, Washington, DC.

Forbes, I. 1952. Chromosome numbers and hybrids in Zoysia. Agron. J. 44:194-199.

Galbraith, D. 2009. Simultaneous flow cytometric quantification of plant nuclear DNA contents over the full range of described angiosperm 2C values. Cytometry 75A:692-698.

Gould, F.W. and T.R. Soderstrom. 1974. Chromosome numbers of some Ceylon grasses. Can. J. Bot. 52:1075-1090.

Gurgel, R.G.A. and M. Ito. 2000. Zoysia grass plant named 'SS-500'. U.S. Plant Patent 11466. U.S. Patent Trademark Office, Washington, DC.

Halfmann, R., D. Stelly, and D. Young. 2007. Towards improved cell cycle synchronization and chromosome preparation methods in cotton. J. Cotton Sci. 11:60-67.

Hampl, V., A. Pavlícek, and J. Flegr. 2001. Construction and bootstrap analysis of DNA fingerprinting-based phylogenetic trees with a freeware program FreeTree: Application to trichomonad parasites. Intl. J. Syst. Evol. Microbiol. 51:731-735.

Hanna, W.W. and J.E. Elsner. 1999. Registration of 'TifEagle' bermudagrass. Crop Sci. 39:1258.

Harris-Shultz, K.R., S.R. Milla-Lewis, and J.A. Brady. 2012. Transferability of SSR and RGA markers developed in Cynodon spp. to Zoysia spp. Plant Mol. Biol. Rpt. 30:1264-1269.

Harris-Shultz, K.R., P. Raymer, B.E. Scheffler, and R.S. Arias. 2013. Development and characterization of seashore paspalum SSR markers. Crop Sci. 53:2679-2685.

Harris-Shultz, K.R., B.M. Schwartz, and J.A. Brady. 2011. Identification of simple sequence repeat markers that differentiate bermudagrass cultivars derived from 'Tifgreen'. J. Amer. Soc. Hort. Sci. 136:211-218.

Jessup, R.W., K. Renganayaki, J.A. Reinart, A.D. Genovesi, M.C. Engelke, A.H. Paterson, T.L. Kamps, S. Schulze, A.N. Howard,
B. Giliberto, and B.L. Burson. 2011. Genetic mapping of fall armyworm resistance in zoysiagrass. Crop Sci. 51:1774-1783.

Kamps, T.L., N.R. Williams, V.M. Ortega, K.C. Chamusco, K.R. Harris-Shultz, B.T. Scully, and C.D. Chase. 2011. DNA polymorphisms at bermudagrass microsatellite loci and their use in genotype fingerprinting. Crop Sci. 51:1-10.

Karaca, M., S. Saha, A. Zipf, J.N. Jenkins, and D.J. Lang. 2002. Genetic diversity among forage bermudagrass (Cynodon spp.): Evidence from chloroplast and nuclear DNA fingerprinting. Crop Sci. 42:2118-2127.

Kimball, J., M. Zuleta, K. Harris-Shultz, K. Kenworthy, V. Lehman, and S. Milla-Lewis. 2012a. Genetic relationships in Zoysia and the identification of putative interspecific hybrids using simple sequence repeat markers and inflorescence traits. Crop Sci. 53:285-295.

Kimball, J., M. Zuleta, M. Martin, K. Kenworthy, A. Chandra, and S. Milla-Lewis. 2012b. Assessment of molecular variation within 'Raleigh' st. augustinegrass using amplified fragment length polymorphism markers. HortScience 47:839-844.

La Mantia, J., X. Wang, M.L. Binzel, and A. Chandra. 2011. Isolation and characterization of eight polymorphic microsatellite loci from Zoysia matrella (L.). Merr. J. Plant Genet. Transgenics 2:1-4.

Li, M., N. Yuyama, M. Hirata, J. Han, Y. Wang, and H. Cai. 2009. Construction of a high-density SSR marker-based linkage map of zoysiagrass (Zoysia japonica Steud.). Euphytica 170:327-339.

Li, M., N. Yuyama, M. Hirata, Y. Wang, J. Han, and H. Cai. 2010. An integrated SSR based linkage map for Zoysia matrella L. and Z. japonica Steud. Mol. Breed. 26:467-476.

Ma, K., D. Jang, A. Dixit, J. Chung, S. Lee, J. Lee, H. Kang, S. Kim, and Y. Park. 2007. Characterization of 30 new microsatellite markers, developed from enriched genomic DNA library of zoysiagrass Zoysia japonica Steud. Mol. Ecol. Notes 7:1323-1325.

McCullough, P.E., J. Yu, and D.G. de Barreda. 2013. Efficacy of preemergence herbicides for controlling a dinitroaniline-resistant goosegrass (Eleusine indica) in Georgia. Weed Technol. 27:639644.

Nei, M. and W.H. Li. 1979. Mathematical model for studying genetic variation in terms of restriction endonucleases. Proc. Natl. Acad. Sci. USA 76:5269-5273.

Patton, A.J. 2009. Selecting zoysiagrass cultivars: Turfgrass quality, growth, test and environmental stress tolerance. Appl. Turfgrass Sci. doi: 10.1094/ATS-2009-1019-01-MG.

Pfosser, M., A. Amon, T. Lelley, and E. Heberle-Bors. 1995. Evaluation of sensitivity of flow cytometry in detecting aneuploidy in wheat using disomic and ditelosomic wheat-rye addition lines. Cytometry 21:387-393.

Rohlf, F.J. 2008. NTSYSpc: Numerical taxonomy system. Version 2.20. Exeter Publ., Setauket, NY.

Schwartz, B.M., K.E. Kenworthy, M.C. Engelke, A.D. Genovesi, R.M. Odom, and K.H. Quesenberry. 2010. Variation in 2C nuclear DNA content of Zoysia spp. as determined by flow cytometry. Crop Sci. 50:1519-1525.

Taliaferro, C.M. 1995. Diversity and vulnerability of bermuda turfgrass species. Crop Sci. 35:327-332.

Tsuruta, S.-I., M. Hashiguchi, M. Ebina, T. Matsuo, T. Yamamoto, M. Kobayashi, M. Takahara, H. Nakagawa, and R. Akashi. 2005. Development and characterization of simple sequence repeat markers in Zoysia japonica Steud. Grassland Sci. 51:249-257.

Waltz, C., Z. Chen, and D. Han. 2005. Emerald zoysiagrass: Is it what it appears to be? GTA Today 20:3-5.

Wang, Z., Y. Wu, D.L. Martin, H. Gao, T. Samuels, and C. Tan. 2010. Identification of vegetatively propagated turf bermudagrass cultivars using simple sequence repeat markers. Crop Sci. 50:2103-2111.

Weng, J., M. Fan, C. Lin, Y.-H. Liu, and S. Huang. 2007. Genetic variation of Zoysia as revealed by random amplified polymorphic DNA (RAPD) and isozyme pattern. Plant Prod. Sci. 10:80-85.

Yaneshita, M., S. Kaneko, and T. Saskuma. 1999. Allotetraploidy of Zoysia species within $2 \mathrm{n}=40$ based on a RFLP genetic map. Theor. Appl. Genet. 98:751-756. 
Supplemental Table 1. Source information for samples collected from six zoysiagrass cultivars from five different states. ${ }^{z}$

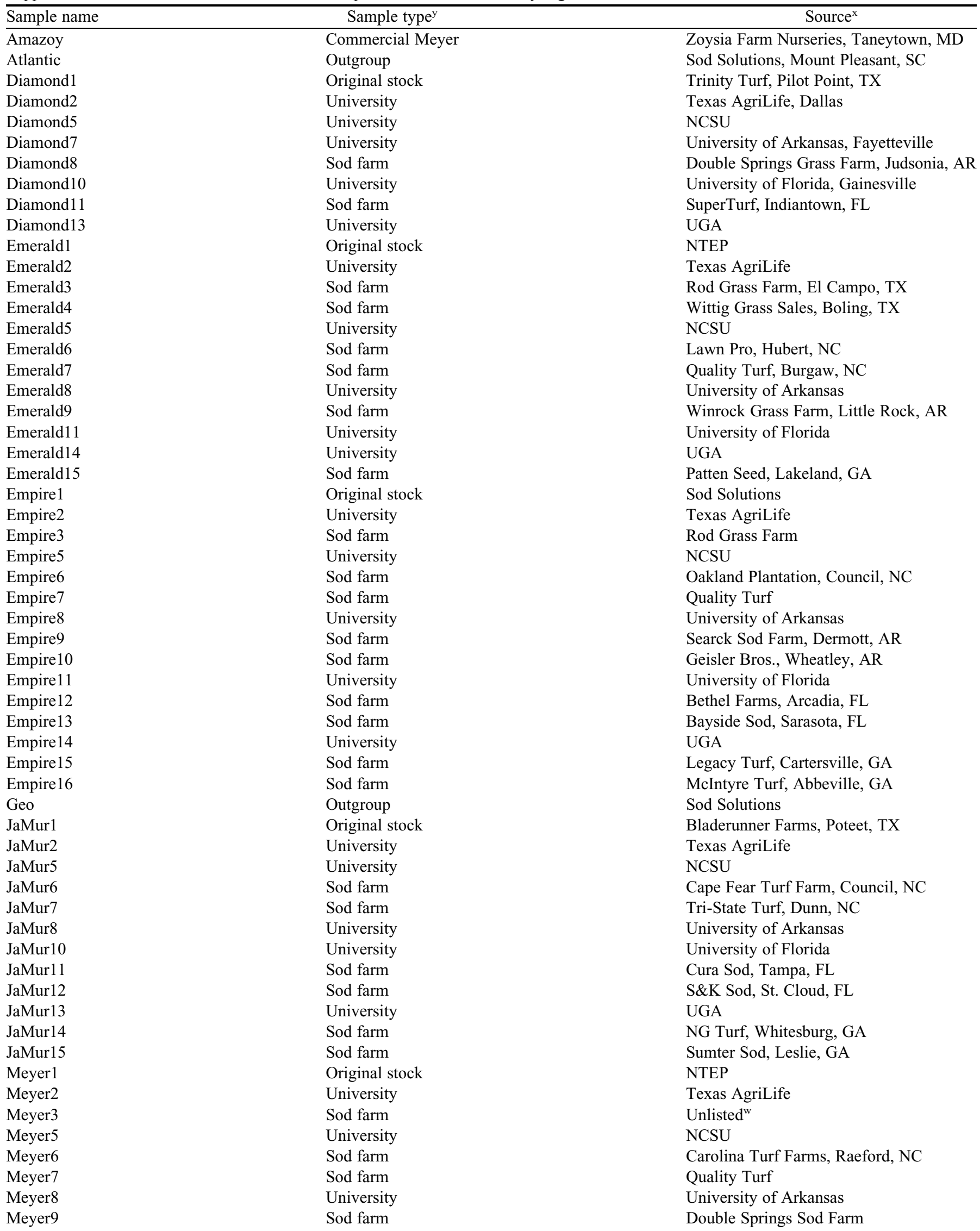


Supplemental Table 1. Continued.

\begin{tabular}{lll}
\hline Sample name & Sample type ${ }^{\mathrm{y}}$ & \multicolumn{1}{c}{ Source $^{\mathrm{x}}$} \\
\hline Meyer10 & Sod farm & Winrock Grass Farm \\
Meyer11 & University & University of Florida \\
Meyer14 & University & UGA \\
Meyer15 & Sod farm & NG Turf \\
Meyer16 & Sod farm & Sod Atlanta, Cartersville, GA \\
Zeon1 & Original stock & Bladerunner Farms \\
Zeon2 & University & Texas AgriLife \\
Zeon3 & Sod farm & Tri-Tex Grass, Tioga, TX \\
Zeon4 & Sod farm & Rod Grass Farm \\
Zeon5 & University & NCSU \\
Zeon6 & Sod farm & Sandhills Turf, Eagle Springs, NC \\
Zeon7 & Sod farm & Tri-State Turf \\
Zeon8 & University & University of Arkansas \\
Zeon10 & University & University of Florida \\
Zeon13 & University & UGA \\
Zeon14 & Sod farm & Sod Atlanta \\
Zeon15 & Sod farm & NG Turf
\end{tabular}

${ }^{ } \mathrm{K}$. Harris-Shultz and C. Waltz were responsible for samples from Georgia, A. Patton was responsible for the Arkansas samples, S. Milla-Lewis was responsible for samples from North Carolina, A. Chandra was responsible from samples obtained from Texas, and K. Kenworthy and K. Harris-Shultz were responsible for samples from Florida.

${ }^{y}$ Commercial Meyer = 'Meyer' grown under another name and sold; Outgroup = a cultivar that was not one of the six cultivars examined that was presumed to be genetically different from the six cultivars; Original stock = reference sample used to compare the genetic purity of samples collected from universities and sod farms.

${ }^{\mathrm{x}} \mathrm{NCSU}=$ North Carolina State University, Raleigh; UGA = University of Georgia, Tifton; NTEP = National Turfgrass Evaluation Program, Beltsville, MD.

${ }^{\text {w}}$ Sod farm owner asked to be unlisted. 


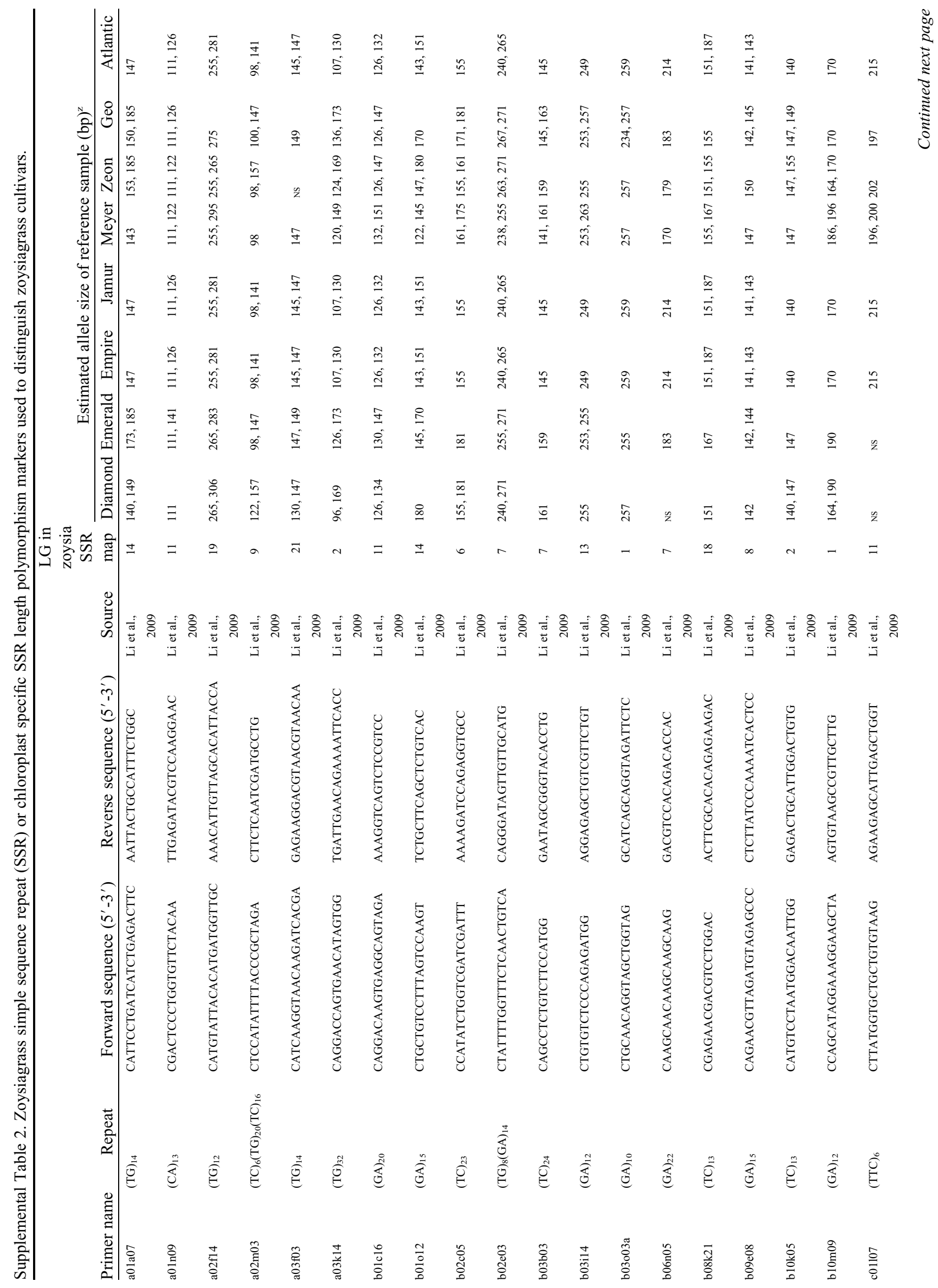




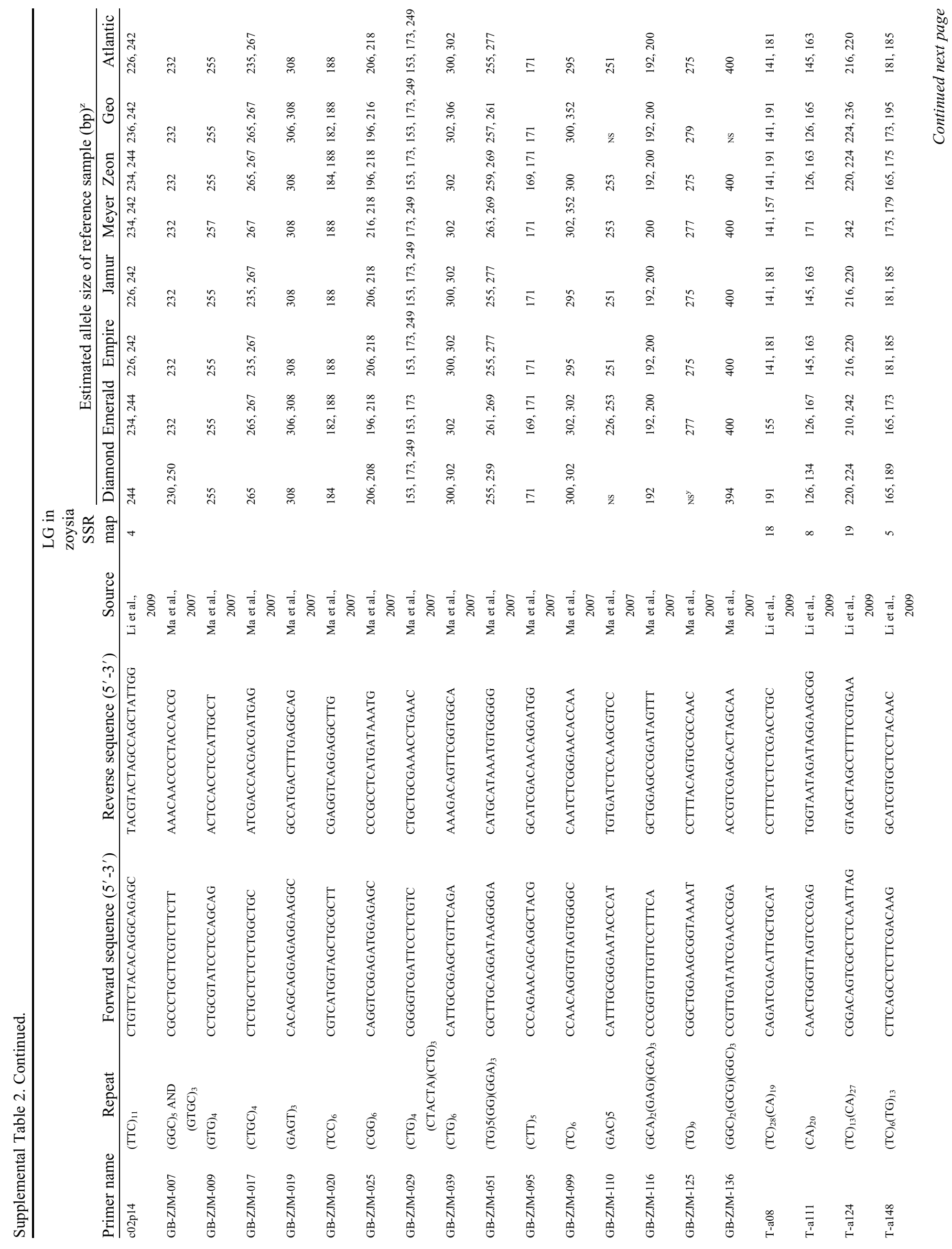




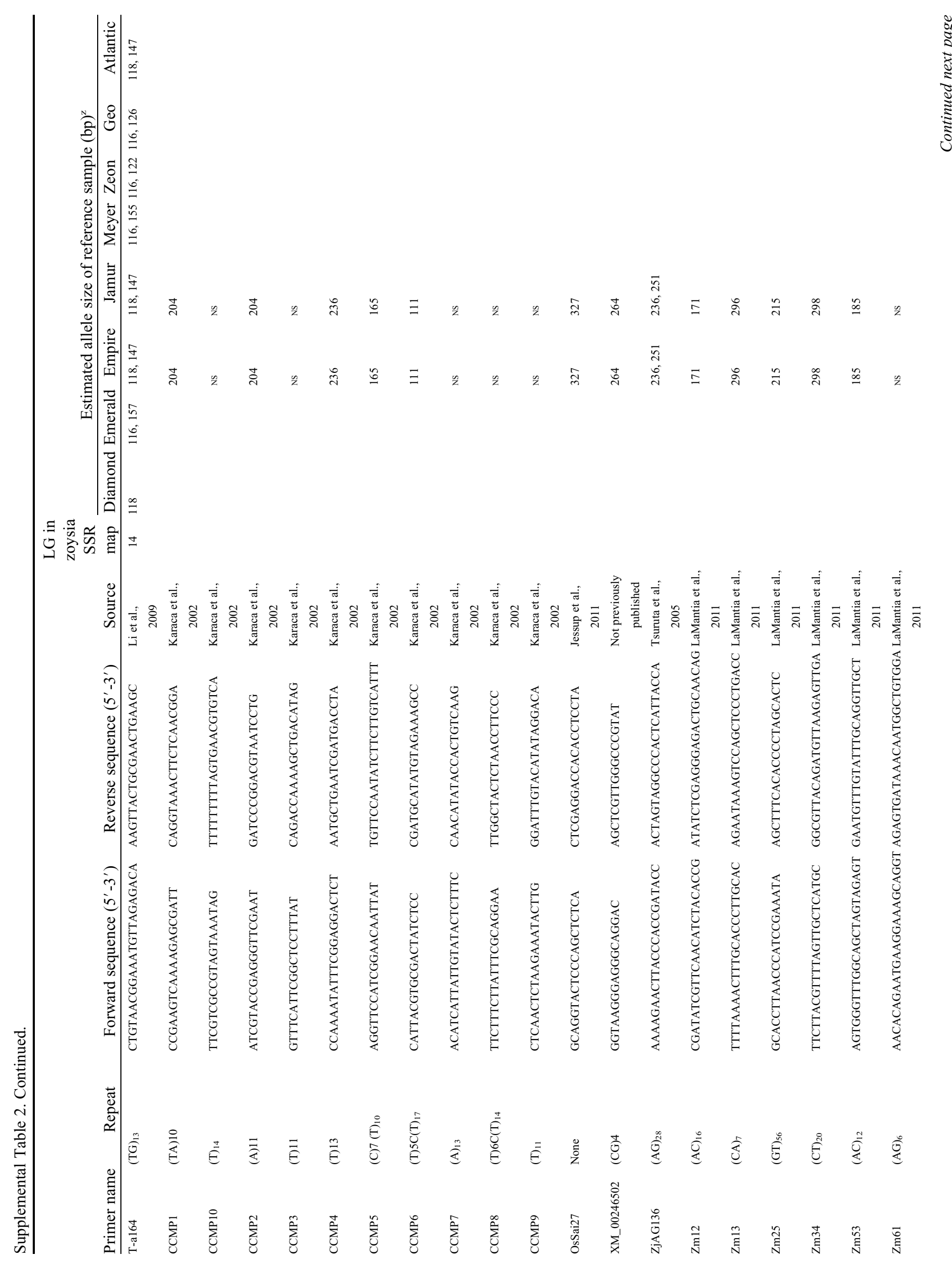




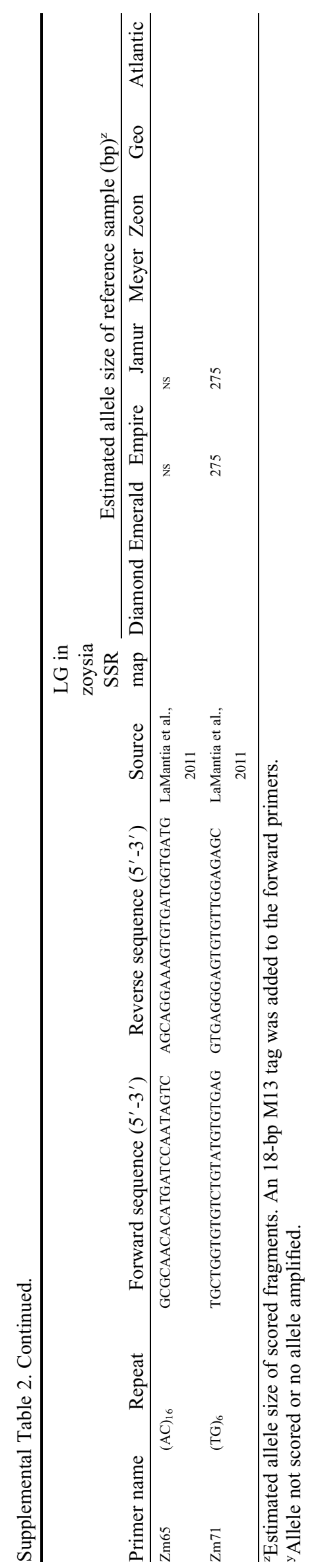

